\title{
Spinal Cord Stimulation (SCS) for Pain Control in a Quadriplegic Patient: A Case Report
}

\author{
Arun Angelo Patil ${ }^{*}$, Jason Loden², Soubrata Raikar ${ }^{3}$, Rita Lee Fowler ${ }^{3}$ \\ ${ }^{1}$ Creighton University Medical Center, Omaha, USA \\ ${ }^{2}$ Surgery Resident, Creighton University Medical Center, Omaha, USA \\ ${ }^{3}$ Midwest Anesthesia Pain Management, Omaha, USA \\ Email: *arun.patil@alegent.org
}

Received 16 October 2015; accepted 8 January 2016; published 12 January 2016

Copyright (C) 2016 by authors and Scientific Research Publishing Inc.

This work is licensed under the Creative Commons Attribution International License (CC BY). http://creativecommons.org/licenses/by/4.0/

(c) (i) Open Access

\section{Abstract}

Background: There are reports of pain relief from spinal cord stimulation (SCS) in patients with incomplete spinal cord injuries. However, the results for pain relief from SCS in patients with complete spinal cord injury are dismal. Patients with complete spinal cord injury therefore are generally not considered suitable candidates for SCS. The authors report a case in which a quadriplegic patient with cervical spinal cord injury got significant pain relief from spinal cord stimulation. Methods: The patient is 41 years old with quadriplegia secondary to C5-6 injury. He has no function below the level of the injury except for a few patchy areas of sensation. Ten years after the injury the patient had hemorrhoidectomy. This resulted in severe pain in the anal pain. The treatment for pain failed conservative treatment. He however did have good response to a trial of spinal cord stimulation through an epidural lead placed at T8-T9 vertebral body level. Permanent implantation of spinal cord stimulator was therefore performed. Results: At preoperative evaluation the patient rated his pain as a $7 / 10$. Presently at 2 years' follow-up the patient rates his pain at 1/10. Conclusions: Spinal cord stimulation proved to be a successful means of achieving adequate pain relief in a patient who had complete loss of motor function below the level of the injury. Therefore, although patients with such condition are unlike to benefit from SCS it is worthwhile trying this treatment if no other option is available there.

\section{Keywords}

Spinal Cord Injury, Chronic Pain, Spinal Cord Stimulation

\footnotetext{
"Corresponding author.
} 


\section{Introduction}

Spinal cord stimulation (SCS) is an accepted method of treatment for patients with failed back syndrome who failed all conservative treatment modalities. This modality involves a relative simple operative procedure that does not significantly affect the spinal structure. It has resulted in improved quality of life, decreased pharmacologic drug use, and has enabled patients to return to work [1]-[6]. In addition to failed back syndrome, SCS has also been used for patients with peripheral vascular disease (PVD) [7]-[9], complex regional pain syndrome [10] [11], peripheral neuropathy [12] [13], and angina [14] [15] with relatively good success.

Unfortunately, the majority of literature regarding the use of SCS for central pain after spinal cord injury is not promising [16]-[19]. Even those papers that report success [20] the patient did not have significant motor or sensory loss. The authors therefore report a quadriplegic patient who obtained excellent pain control following implantation of SCS.

\section{Methods/Results}

The patient is a 41-year-old male who sustained a C5 - C6 fracture which resulted in complete motor loss below the level of the injury. Sensory examination showed patchy areas of sensation in the lower extremities (including the saddle area) but the findings were not consistent. Ten years later he had hemorrhoidectomy. Following this, he began experiencing pain in the lower back area and in the anal area. It was burning in nature and was associated with muscle spasms in the muscles around the pain. The pain was worse with defecation and sitting, and relieved by lying down. He reported a pain level of 7/10.

Several treatment modalities were tried. They included: opioid analgesics baclofen, sphincter injection with steroids and local anesthetics, multiple L5, S1, S2 radiofrequency (RF) rhizotomies, bilateral SI joint injection with steroids and RF ablation of SI joints. None of these treatments gave him permanent relief.

Three years following pain onset, the patient had a SCS trial. Two trial leads were percutaneously implanted through a Touhy needle. The active contacts were placed at the T8 - T9 vertebral body level. A stimulation trial was then done for 5 days. During these 5 days the patient had very good relief of pain. The lead was then removed and 4 weeks later implantation of the permanent spinal cord stimulation system was done. The procedure was done under general anesthesia. Through a laminotomy opening a paddle lead was implanted in theepidural space at the level of T8 and T9 vertebral bodies. The area of paresthesia produced by the stimulation included the area of his pain. The system was programmed to give optimal pain relief. At 2 years follow up the patients pain scale is $1 / 10$ and the patient is off all pain medications.

\section{Discussion}

The neurophysiological mechanism for pain suppression in neuropathic and ischemic pain following spinal cord stimulation has been studied. It is suspected that neuropathic pain is suppressed by depressing the hyper excitability of the neurons in the dorsal horn. This is accomplished by increasing the level of GABA and serotonin resulting in suppression of excitatory amino acids-glutamate and aspartate. Ischemic pain is relieved by inhibiting the sympathetic nervous system. Melzack and Wall proposed the "gate theory" for pain control using the SCS system [21]. They hypothesized that input into the spinal cord from nerves carrying touch and vibratory sensation could be manipulated by a stimulator to block- "close the gate"- the input from nerve fibers carrying pain sensation. However, the exact mechanism of action of the SCS still remains unknown.

It is common to experience pain after spinal cord injury, and most of them can be managed [18] [22] [23] through different treatment modalities available. Muscle spasm pain arises in an area of preserved sensory fibers which lack appropriate inhibition leading to increased spasticity. Antispasmodics medications can help the patients with this condition [24]. Visceral pain occurs intermittently and sporadically several months to years following the initial injury. It arises from abdominal myoneural dysfunction and is often associated with referred pain. It is difficult to treat given its transient nature and its lack of localization [24]. Neuropathic pain is due to damage or dysfunction of any part of the nervous system. It is described as sharp, burning, and shooting sensation. There is often direct nerve tissue injury which results in an inappropriate trafficking of signal. These signals are relayed through alternative routes where they produce a change of function creating the sensation of pain. Nonsteroidal anti-inflammatory drugs can provide some relief [24] [25]. Segmental pain begins days to weeks following an injury. Typically, it is located directly above or below the level of injury at the boundary of normal sensation and loss of sensation. SCS often will provide excellent relief for this type of pain [24]. Nerve 
root entrapment has a predictable radicular pattern and occurs below the level of the injury. Decompression is the treatment of choice [24]. Syringomyelia pain is rare. It presents months to years following injury as the syrinx expands. Surgical intervention is required if daily symptoms are present [24].

Although there has been success in using the SCS system for failed back syndrome, its use for central or deafferentation pain has not been very encouraging [5] [8] [12] [13] [16] [22] [26]-[28]. This pain is below the level of injury and is diffuse with burning and dysesthetic character [29].The exact mechanism for this type of pain is unknown [2] [5] [30], and is different from the pain associated with muscle spasms [7] [17]. Some authors attribute this pain to an imbalance between the preserved dorsal column and the damaged spinothalamic system [31]. Therefore to get relief from SCS integrity of the lemniscal tract is needed [27]. The probability to have this integrity is higher in patients with incomplete lesions. This might explain why some patients with incomplete lesions have been successful in achieving pain relief [20]. Conversely, in patient with complete lesion the probability to have intact lemniscal fibers is almost zero. The patient presented in this paper did have complete motor loss below the injury but he does have patchy areas in which he had some sensation. It is therefore possible that he has some preservation of the lemniscal fibers. This might be a reason why SCS helped him with surprisingly good results. This indicates that even in patients with complete motor loss and only patchy areas of sensation may benefit from SCS.

\section{Conclusion}

In summary, SCS was successful in obtaining pain relief in patients with complete spinal cord injury with only patchy areas of preserved sensation. This indicates that structures needed for relief of pain relief from SCS may still be intact in such patients. Therefore it may be worthwhile considering this option if nothing else proves useful.

\section{Acknowledgements}

There is no conflict of interest for any of the authors.

\section{References}

[1] Cameron, T. (2004) Safety and Efficacy of Spinal Cord Stimulation for the Treatment of Chronic Pain: A 20-year Literature Review. Journal of Neurosurgery, 100, 254-267.

[2] De Vries, J., De Jongste, M.J., Spincemaille, G. and Staal, M.J. (2007) Spinal Cord Stimulation for Ischemic Heart Disease and Peripheral Vascular Disease. Advances and Technical Standards in Neurosurgery, 32, 63-89. http://dx.doi.org/10.1007/978-3-211-47423-5_4

[3] Kumar, K., Hunter, G. and Demeria, D. (2006) Spinal Cord Stimulation in Treatment of Chronic Benign Pain: Challenges in Treatment Planning and Present Status, a 22-Year Experience. Neurosurgery, 58, 481-496. http://dx.doi.org/10.1227/01.NEU.0000192162.99567.96

[4] Kumar, K., Nath, R. and Wyant, G.M. (1991) Treatment of Chronic Pain by Epidural Spinal Cord Stimulation: A 10-Year Experience. Journal of Neurosurgery, 75, 402-407. http://dx.doi.org/10.3171/jns.1991.75.3.0402

[5] Kumar, K., Taylor, R.S., Jacques, L., Eldabe, S., Meglio, M., Molet, J., Thomson, S., O’Callaghan, J., Eisenberg, E., Milbouw, G., Buchser, E., Fortini, G., Richardson, J. and North, R.B. (2008) The Effects of Spinal Cord Stimulation in Neuropathic Pain Are Sustained: A 24-Month Follow-Up of the Prospective Randomized Controlled Multicenter Trial of the Effectiveness of Spinal Cord Stimulation. Neurosurgery, 63, 762-770. http://dx.doi.org/10.1227/01.NEU.0000325731.46702.D9

[6] Oakley, J. (2003) Spinal Cord Stimulation: Patient Selection, Technique, and Outcomes. Neurosurgery Clinics of North America, 14, 365-380. http://dx.doi.org/10.1016/S1042-3680(03)00011-1

[7] Amann, W., Berg, P., Gersbach, P., Gamain, J., Raphael, J.H. and Ubbink, D.T. (2003) Spinal Cord Stimulation in the Treatment of Nonreconstructable Stable Critical Leg Ischaemia: Results of the European Peripheral Vascular Disease Outcome Study (SCSEPOS). European Journal of Vascular and Endovascular Surgery, 26, 280-286. http://dx.doi.org/10.1053/ejvs.2002.1876

[8] Davidoff, G., Roth, E., Guarracini, M., Guarracini, M., Sliwa, J. and Yarkony, G. (1987) Function-Limiting Dysesthetic Pain Syndrome among Traumatic Spinal Cord Injury Patients: A Cross-Sectional Study. Pain, 29, 39-48. http://dx.doi.org/10.1016/0304-3959(87)90176-X

[9] Horsch, S., Schulte, S. and Hess, S. (2004) Spinal Cord Stimulation in the Treatment of Peripheral Vascular Disease: Results of a Single Center Study of 258 Patients. Angiology, 55, 111-118. 
http://dx.doi.org/10.1177/000331970405500201

[10] Harke, H., Gretenkort, P., Ladleif, H.U. and Rahman, S. (2005) Spinal Cord Stimulation in Sympathetically Maintained Complex Regional Pain Syndrome Type I with Severe Disability. A Prospective Clinical Study. European Journal of Pain, 9, 363-373. http://dx.doi.org/10.1016/j.ejpain.2004.09.003

[11] Taylor, R.S., Van Buyten, J.P. and Buchser, E. (2006) Spinal Cord Stimulation for Complex Regional Pain Syndrome: A Systematic Review of the Clinical and Cost-Effectiveness Literature and Assessment of Prognostic Factors. European Journal of Pain, 10, 91-101. http://dx.doi.org/10.1016/j.ejpain.2005.02.004

[12] Daousi, C., Benbow, S.J. and MacFarlane, I.A. (2005) Electrical Spinal Cord Stimulation in the Long-Term Treatment of Chronic Painful Diabetic Neuropathy. Diabetic Medicine, 22, 393-398. http://dx.doi.org/10.1111/j.1464-5491.2004.01410.x

[13] Fogel, G.R., Esses, S.I. and Calvillo, O. (2003) Management of Chronic Limb Pain with Spinal Cord Stimulation. Pain Practice, 3, 144-151. http://dx.doi.org/10.1046/j.1533-2500.2003.03021.x

[14] Ansari, S., Chaudhri, K. and Moutaery, K. (2007) Neurostimulation for Refractory Angina Pectoris. Acta Neurochirurgica Supplement, 97, 283-288.

[15] Taylor, R.S., De Vries, J., Buchser, E. and De Jongste, M.J. (2009) Spinal Cord Stimulation in the Treatment of Refractory Angina: Systematic Review and Meta-Analysis of Randomised Controlled Trials. BMC Cardiovascular Disorders, 9, 13. http://dx.doi.org/10.1186/1471-2261-9-13

[16] Balazy, T.E. (1992) Clinical Management of Chronic Pain in Spinal Cord Injury. Clinical Journal of Pain, 8, $102-110$. http://dx.doi.org/10.1097/00002508-199206000-00007

[17] Brittel, C.W. and Mariano, A.J. (1991) Chronic Pain in Spinal Cord Injury. In: Walsh, N.E., Ed., Physical Medicine and Rehabilitation: State of the Art Reviews, Hanley \& Belfus, Philadelphia, 71-82.

[18] Burke, D.C. and Woodward, J.M. (1976) Pain and Phantom Sensation in Spinal Paralysis. In: Vinken, P.J. and Bruyn, G.W., Eds., Handbook of Clinical Neurology, North-Holland Publishing, Amsterdam, 489-499.

[19] Meglio, M., Cioni, B. and Rossi, G.F. (1990) Spinal Cord Stimulation in Management of Chronic Pain: A 9-Year Experience. Journal of Neurosurgery, 70, 519-524. http://dx.doi.org/10.3171/jns.1989.70.4.0519

[20] Lee, M.G., Choi, S.S., Lee, M.K., Kong, M.H., Lee, I.O. and Oh, H.R. (2009) Thoracic Spinal Cord Stimulation for Neuropathic Pain after Spinal Meningioma Removal: A Case Report. Clinical Journal of Pain, 25, 167-169. http://dx.doi.org/10.1097/AJP.0b013e3181839ad8

[21] Melzack, R. and Wall, P.D. (1965) Pain Mechanisms: A New Theory. Science, 150, 971-979. http://dx.doi.org/10.1126/science.150.3699.971

[22] Bonica, J.J. (1991) Introduction: Semantic, Epidemiologic, and Educational Issues. In: Casey, K.L., Ed., Pain and Central Nervous System Disease: The Central Pain Syndromes, Raven Press, New York, 13-30.

[23] Cioni, B., Meglio, M., Pentimalli, L. and Visocchi, M. (1995) Spinal Cord Stimulation in the Treatment of Paraplegic Pain. Journal of Neurosurgery, 82, 35-39. http://dx.doi.org/10.3171/jns.1995.82.1.0035

[24] Siddall, P.J. and Loeser, J.D. (2002) Pain Following Spinal Cord Injury. Spinal Cord 2002.

[25] Deer, T.R. and Raso, L.J. (2006) Spinal Cord Stimulation for Refractory Angina Pectoris and Peripheral Vascular Disease. Pain Physician, 9, 347-352.

[26] Arnér, S. and Meyerson, B.A. (1988) Lack of Analgesic Effect of Opioids on Neuropathic and Idiopathic Forms of Pain. Pain, 33, 11-23. http://dx.doi.org/10.1016/0304-3959(88)90198-4

[27] North, R.B., Ewend, M.G., Lawton, M.T., Kidd, D.H. and Piantadosi, S. (1991) Failed Back Surgery Syndrome: 5Year Follow-Up after Spinal Cord Stimulator Implantation. Neurosurgery, 28, 692-699. http://dx.doi.org/10.1227/00006123-199105000-00009

[28] Wester, K. (1987) Dorsal Column Stimulation in Pain Treatment. Acta Neurologica Scandinavica, 75, 151-155. http://dx.doi.org/10.1111/j.1600-0404.1987.tb07910.x

[29] Illis, L.S. (1991) Central Pain. British Medical Journal, 300, 1284-1286. http://dx.doi.org/10.1136/bmj.300.6735.1284

[30] Oakley, J. and Prager, J. (2002) Spinal Cord Stimulation: Mechanism of Action. Spine, 27, 2574-2583. http://dx.doi.org/10.1097/00007632-200211150-00034

[31] Beric, A., Dimitrijevic, M.R. and Lindblom, U. (1988) Central Dysesthesia Syndrome in Spinal Cord Injury Patients. Pain, 34, 109-116. http://dx.doi.org/10.1016/0304-3959(88)90155-8 